\title{
Risk of breast, ovary, and uterine corpus cancers among 85268 women with AIDS
}

\author{
JJ Goedert*, , C Schairer ${ }^{2}$, TS McNeel ${ }^{3}$, NA Hessol ${ }^{4}$, CS Rabkin' and EA Engels' for the HIVIAIDS Cancer \\ Match Study ${ }^{5}$
}

'Viral Epidemiology Branch, Division of Cancer Epidemiology and Genetics, National Cancer Institute, Rockville, MD 20892, USA; ${ }^{2}$ Biostatistics Branch, Division of Cancer Epidemiology and Genetics, National Cancer Institute, Rockville, MD 20892, USA; ${ }^{3}$ Information Management Services, Inc., Silver Spring, MD 20904, USA; ${ }^{4}$ Department of Medicine, University of California, San Francisco, CA 94 I 22, USA

By linking HIVIAIDS and cancer surveillance data in 12 US regions, breast and reproductive cancer risks with AIDS were compared to those in the general population. Trends in standardized incidence ratios (SIRs) were assessed by CD4 count, AIDS-relative time, and calendar time. Standardized incidence ratios were indirectly adjusted for cancer risk factors using data from AIDS cohort participants and the general population. With AIDS, 3 I 3 women developed breast cancer (SIR 0.69, 95\% confidence interval (Cl) 0.62-0.77), 42 developed ovary cancer (SIR I.05, 95\% Cl, 0.75-I.42), and 3I developed uterine corpus cancer (SIR 0.57, 95\% Cl, 0.39-0.8I). Uterine cancer risk was reduced significantly after age 50 (SIR 0.33). Breast cancer risk was reduced significantly both before (SIR $0.7 \mathrm{I}$ ) and after (SIR 0.66) age 50, and was lower for local or regional (SIR 0.54) than distant (SIR 0.89) disease. Breast cancer risk varied little by CD4 count $\left(P_{\text {trend }}=0.47\right)$ or AIDS-relative time $\left(P_{\text {trend }}=0.14\right)$ or after adjustment for established cancer risk factors. However, it increased significantly between 1980 and $2002\left(P_{\text {trend }}=0.003\right)$, approaching the risk of the general population. We conclude that the cancer deficit reflected direct or indirect effects of HIVIAIDS and that anti-HIV therapy reduced these effects. British Journal of Cancer (2006) 95, 642-648. doi:I0.1038/sj.bjc.6603282 www.bjcancer.com

Published online 25 July 2006

(c) 2006 Cancer Research UK

Keywords: breast cancer; endometrial cancer; ovarian cancer; human immunodeficiency virus (HIV); acquired immunodeficiency syndrome (AIDS); risk factors

Increasing numbers of women have been infected with human immunodeficiency virus (HIV) and now are living with the acquired immunodeficiency syndrome (AIDS). The effects of AIDS on women, particularly in the era of highly active antiretroviral therapy (HAART), are not well defined. In the era before HAART, the risks of developing Kaposi sarcoma, anal cancer, and perhaps lymphoma were lower for women than for men with AIDS (Beral and Newton, 1998; Goedert, 2000). Other than cervical cancer, no differences by gender have been reported for the few other malignancies found in excess among people with AIDS (PWA) (Goedert et al, 1998; Frisch et al, 2001).

Breast cancer may occur less often in women with AIDS than in the general population (Goedert et al, 1998; Frisch et al, 2001). Ovary and uterine corpus cancers have not been associated with AIDS or other immune deficiencies, but weak associations or susceptible subgroups may have been overlooked because these malignancies are relatively rare. No previous study has evaluated the effects of improving anti-HIV therapies or whether differences in cancer incidence might merely reflect differences in known risk factors for cancer.

Using population-based data, we have investigated whether the risk of breast, ovary, or uterine corpus cancers differ for women with AIDS, whether breast cancer risk differs with increasing

*Correspondence: Professor JJ Goedert; E-mail: goedertj@mail.nih.gov

${ }^{5}$ See Acknowledgements for list of participating registries

Revised I4 June 2006; accepted 29 June 2006; published online 25 July 2006 severity or duration of immune deficiency, or with increasing availability and efficacy of anti-HIV therapies; also whether menopause or selected risk factors modify or explain any associations.

\section{MATERIALS AND METHODS}

\section{Detection and definition of cancers}

From 2003 through 2005, we linked HIV/AIDS and cancer registration data (including name, race, sex, dates of birth and death, and, where available, social security numbers) in 12 regions of the US to identify cancers arising among PWA (Goedert et al, 1998; Frisch et al, 2001; Borges et al, 2001). Ethical and legal reviews at all participating HIV/AIDS and cancer registries ensured that patient confidentiality was maintained.

This study describes the cancer profile of women diagnosed with AIDS from ages 15 to 91 years, referred to below as the registry population. Time at risk, expressed as person-years, was calculated from the start to the end of complete cancer registration in the particular area, no earlier than 60 months before nor later than 120 months after AIDS onset, and censored at death if less than 120 months after AIDS. Although migration could not be determined, both the HIV/AIDS and cancer registries used the National Death Index to ascertain deaths, including those occurring outside the registration areas. The current study included only invasive cancers, coded according to the International Classification of Diseases for Oncology (ICD-O), and analysed by site using the Surveillance, Epidemiology and End Results program's 'Site recode 
with KS and mesothelioma' (Fritz et al, 2000; Ries et al, 2005). Individual cancer sites (ICD-O C50, C54, and C56.9) were analysed after excluding tumours at those sites that had unspecified, KS or NHL histology (codes 8000-8005, 9140, and 9050-9055 or 95909989, respectively).

\section{Measures of relative risk}

Detailed statistical methods are provided in the appendix. Briefly, we used previously described methods to calculate the standardized incidence ratio (SIR), which is the ratio of observed to expected cancers derived from contemporaneous, racial/ethnic ancestry-, age-, and registry-specific population-based incidence rates (Goedert et al, 1998; Frisch et al, 2001). For presentation, ancestry was grouped as African and other. Expected numbers of cancer were calculated as the sum of stratum-specific products of background cancer incidence and person-months at risk among the PWA and were discounted for periods before AIDS onset to account for reduced survival following a cancer diagnosis (Breslow and Day, 1987; Grulich et al, 1999; Frisch et al, 2000; Engels et al, 2003). We calculated $95 \%$ confidence intervals (CI) assuming a Poisson distribution of the observed cancers (Breslow and Day, 1987). For an overall SIR estimate, we used the 15-year period from 60 months before to 120 months after AIDS onset. All subgroup and trend analyses were preplanned. To estimate cancer risk before and after menopause, SIRs were calculated by age at cancer diagnosis, grouped as $<50$ and $\geqslant 50$ years.

We used Poisson modeling and a two-sided score test (Goedert et al, 1998; Frisch et al, 2001) to evaluate change in SIR across six AIDS-relative time intervals, as presented. We excluded the AIDS onset period ( 6 months before to 3 months after AIDS onset) from the trend test to reduce the influence of ascertainment bias from the generally increased diagnostic activity around the time of AIDS diagnosis. A similar approach was used to evaluate change in SIR across CD4 lymphocyte count at AIDS onset (limited to years 1990-2002 because CD4 data generally were not available before 1990) and across calendar intervals (limited to 4-27 months after AIDS onset to focus on an interval when follow-up would be most complete). In sensitivity analyses (not presented), we found no difference in the trend in breast cancer SIR with an alternative time interval (4-60 months after AIDS onset) or calendar intervals (1980-1986, 1987-1995, 1996-2002). To further assess trends in SIR, we used Poisson regression to fit linear models for breast cancer risk across calendar time (1980-2002). Although women with HIV/AIDS had lower fertility and BMI in the pre-HAART era, (Lee et al, 2000; Forsyth et al, 2002), the breast cancer deficit with AIDS was minimally altered by adjustment for these factors.

\section{Indirect adjustment}

We used indirect methods to adjust for the different prevalence of selected cancer risk factors in PWA as compared to the general population (Steenland and Greenland, 2004). Details are provided in the Appendix. For the general US population, prevalence data on age at first live birth, parity, body mass index (BMI), cigarette smoking, and oral contraceptive use were derived from a weighted average of women in the $1987(n=24898)$ and $2000(n=24503)$ National Health Interview Surveys (NHIS) (Centers for Disease Control and Prevention, 2002). For women with AIDS, prevalence data on these risk factors were obtained from female participants with AIDS (henceforth referred to as AIDS patients) in the AIDS Cancer Cohort Study $(n=483)$ or the Women's Interagency HIV Study (WIHS, $n=693$ ) (Barkan et al, 1998; Nawar et al, 2005). These two studies included subjects from six of the HIV/AIDS registry areas (New York City, Los Angeles, San Francisco, Florida, Massachusetts, and Connecticut), and the demographic characteristics of the AIDS patients resembled those of our registry population and of the national female HIV/AIDS population
(Bacon et al, 2005). The majority (59\%) of participants in WIHS were below the Federal poverty level, and $13 \%$ did not reside in a house or apartment (Barkan et al, 1998). We excluded AIDS patients and NHIS women who had a history of breast cancer.

For breast cancer, we adjusted for the effects of age at first live birth or nulliparity and BMI with age-specific relative risks (RRs) (MacMahon et al, 1970; Ballard-Barbash and Swanson, 1996; Friedenreich, 2001; Althuis et al, 2003). In a sensitivity analysis that yielded similar results (not presented), we used African American-specific RRs (Zhu et al, 2005). For uterine corpus cancer, we adjusted for the joint effects of parity and cigarette smoking with age-specific RRs (Brinton et al, 1992; Viswanathan et al, 2005). As a result of sparse data, we separately evaluated the effect on uterine corpus cancer of BMI (Ballard-Barbash and Swanson, 1996). We did not adjust for effects of oral contraceptive use because prevalence of use did not vary materially between the AIDS patients and the NHIS (data not presented).

\section{RESULTS}

In linkages performed during 2003-2005 in 12 regions of the US with population-based cancer ascertainment, 85268 women were followed for 665987 person-years, measured from 5 years before to 10 years after an initial AIDS diagnosis. There were 51616 women of African ancestry (61\%), 17705 women of Hispanic ancestry (21\%), 15019 non-Hispanic women of European ancestry (18\%), and 928 women of other or missing ancestry (1\%). At AIDS diagnosis, median age of the women was 36 years (interquartile range $31-43$ years); $90 \%$ of the women were age 50 years or younger.

The incidence of breast and uterine corpus cancers, but not of ovary cancer, was significantly lower than in the general population. Specifically, linkage to the cancer registries revealed 313 cases of breast cancer (SIR 0.69; 95\% CI, $0.62-0.77$ ), 31 cases of uterine corpus cancer (SIR $0.57 ; 95 \% \mathrm{CI}, 0.39-0.81$ ), and 42 cases of ovary cancer (SIR 1.05; 95\% CI, $0.75-1.42$ ) among women with AIDS. Breast cancer SIR was reduced in all groups defined by age at AIDS onset, including those with AIDS onset before age 35 (SIR 0.69). As shown in Table 1, the SIR for breast and ovary cancers did not differ by age at cancer diagnosis, a surrogate for menopause status. In contrast, the uterine corpus cancer SIR differed by menopause status: 0.86 (95\% CI, $0.54-1.32)$ before age 50 and 0.33 (95\% CI, $0.16-0.61)$ at or after age 50 . Standardized incidence ratio did not vary by racial ancestry for any of the three cancers (Table 1). Cancer and AIDS records matched exactly on social security number for 211 (67\%) of the breast cancer cases; the records for the other 102 cases matched on other criteria. Breast cancer SIR did not vary by availability of social security number for matching (Table 2). By stage, breast cancer SIR from 4 to 60 months after AIDS onset was 0.49 (95\% CI, 0.34-0.68) for locally invasive cancer, 0.61 (95\% CI, $0.42-0.86)$ for regional dissemination, and 0.89 (95\% CI, $0.40-1.68$ ) for distant metastases (Table 2). Data for uterine corpus and ovary cancer were too sparse to evaluate by stage.

We examined trends in SIR with respect to time relative to AIDS onset and CD4 count, as measures of immune deficiency (Table 2). Near the time of the initial AIDS-defining condition $(-6$ to +3 months), the SIR was 1.15 (95\% CI, 0.87-1.50) for breast cancer, $1.19(95 \% \mathrm{CI}, 0.48-2.45)$ for uterine corpus cancer, and $2.90(95 \%$ CI, 1.54-4.94) for ovary cancer. Excluding this interval of intensive diagnostic scrutiny, there was no significant trend in the breast cancer SIR from 60 months before to 120 months after AIDS onset $\left(P_{\text {trend }}=0.14\right.$, Table 2$)$. There was no trend with AIDS-relative time in the SIR for uterine corpus cancer or ovary cancer $\left(P_{\text {trend }}=0.72\right.$ and 0.94 , respectively, data not presented). As with the AIDSrelative time analyses, CD4 lymphocyte count at AIDS onset was not significantly associated with SIR for breast cancer 
Table I Standardized incidence ratio (SIR) of cancer among 85268 women from 60 months before to 120 months after an initial AIDSdefining event, $1980-2002^{\mathrm{a}}$

\begin{tabular}{|c|c|c|c|}
\hline \multirow[b]{2}{*}{ Cancer type subgroup ${ }^{b}$} & \multicolumn{2}{|c|}{ Cancer cases } & \multirow{2}{*}{$\begin{array}{c}\text { SIR } \\
(95 \% \mathrm{CI})\end{array}$} \\
\hline & Observed & Expected & \\
\hline Breast cancer & 313 & 453.3 & $0.69(0.62-0.77)$ \\
\hline Premenopausal & 201 & 283.6 & $0.7 \mid(0.6|-0.8|)$ \\
\hline Postmenopausal & 112 & 169.7 & $0.66(0.54-0.79)$ \\
\hline African ancestry & 181 & 248.1 & $0.73(0.63-0.84)$ \\
\hline Other ancestry & 132 & 205.2 & $0.64(0.54-0.76)$ \\
\hline Uterine corpus cancer & 31 & 54.6 & $0.57(0.39-0.81)$ \\
\hline Premenopausal & 21 & 24.3 & $0.86(0.54-1.32)$ \\
\hline Postmenopausal & 10 & 30.3 & $0.33(0.16-0.61)$ \\
\hline African ancestry & 13 & 25.0 & $0.52(0.28-0.89)$ \\
\hline Other ancestry & 18 & 29.6 & $0.61(0.36-0.96)$ \\
\hline Ovary cancer & 42 & 40.1 & $1.05(0.75-1.42)$ \\
\hline Premenopausal & 28 & 25.6 & $1.09(0.73-1.58)$ \\
\hline Postmenopausal & 14 & 14.5 & $0.97(0.53-1.62)$ \\
\hline African ancestry & 23 & 18.5 & $1.25(0.79-1.87)$ \\
\hline Other ancestry & 19 & 21.7 & $0.88(0.53-1.37)$ \\
\hline \multicolumn{4}{|c|}{$\begin{array}{l}\text { aThe } 85268 \text { women, aged } 15-91 \text {, accumulated } 665987 \text { person-years, censored at } \\
\text { death and excluding time before and after the population-based cancer registry in the } \\
\text { same region had complete data. }{ }^{\circ} \text { Other ancestry includes European (including all } \\
\text { Hispanics), other, and missing ancestry. Premenopausal are cancers occurring before } \\
\text { age 50. Postmenopausal are cancers occurring at or after age } 50 \text {. }\end{array}$} \\
\hline
\end{tabular}

$\left(P_{\text {trend }}=0.47\right.$, Table 2$)$ or, based on sparse data, for uterine corpus or ovary cancer $\left(P_{\text {trend }}=0.91\right.$ and 0.89 , respectively, data not presented).

Calendar time was used as a surrogate for availability of antiHIV therapy - little or none pre-1990, single and dual reverse transcriptase inhibitors in 1990-1995, and HAART after 1995. As shown in Table 2, for breast cancer occurring 4 to 27 months after AIDS onset, no cases occurred ( $v s 4.7$ expected) in the cohort with AIDS onset in 1980-1989, whereas the SIR was 0.38 with AIDS onset in 1990-1995, and the SIR was 0.83 with AIDS onset in 1996-2002 $\left(P_{\text {trend }}=0.002\right)$. Excluding the 1980-1989 cohort that had no cases, the SIR still increased significantly $(P=0.01)$ from the 1990-1995 to the 1996-2002 cohort. The significant increase in breast cancer SIR also was found using single calendar years in a Poisson regression model $\left(P_{\text {trend }}=0.003\right.$, Figure 1$)$. Data were very sparse for years $2000-2002$, with only 7.2 breast cancer cases expected. Comparing the 1990-1995 and the 1996-2002 cohorts, risk of local stage breast cancer increased from SIR $0.40(95 \% \mathrm{CI}$, $0.22-0.66)$ to $0.61(95 \% \mathrm{CI}, 0.38-0.93)$. Similarly, risk of regional stage breast cancer risk increased from SIR 0.53 (95\% CI, $0.29-$ $0.88)$ to $0.77(95 \% \mathrm{CI}, 0.47-1.19)$. There was no trend with calendar time in the SIR for uterine corpus cancer, ovary cancer, or distant metastatic breast cancer $\left(P_{\text {trend }} \geqslant 0.5\right)$ but data were sparse.

Indirect adjustment for age at first live birth, nulliparity and BMI had little effect on the breast cancer SIR estimate $\left(\right.$ SIR $_{\text {adj }} 0.72$ vs 0.69 unadjusted). For uterine corpus cancer overall, there was little effect with indirect adjustment for parity and smoking $\left(\mathrm{SIR}_{\mathrm{adj}}\right.$ $0.59)$ or for BMI (SIR adj 0.56$)$ compared to the unadjusted estimate (SIR 0.57). Among postmenopausal women, the SIR for uterine corpus cancer was modestly attenuated with adjustment for parity and smoking (SIR $\left.\mathrm{adj}_{\mathrm{a}} 0.39\right)$ and for BMI (SIR $\mathrm{Sdj}_{\mathrm{adj}} 0.37$, compared to the unadjusted SIR 0.33).

\section{DISCUSSION}

Women with AIDS had a low incidence of locally invasive and regionally disseminated breast cancer, but this cancer deficit
Table 2 Standardized incidence ratio (SIR) of breast cancer among women with AIDS

\begin{tabular}{|c|c|c|c|c|}
\hline & \multicolumn{2}{|c|}{ Breast cancer cases } & \multirow[b]{2}{*}{ SIR } & \multirow[b]{2}{*}{$95 \% \mathrm{Cl}$} \\
\hline & Observed & Expected & & \\
\hline \multicolumn{5}{|c|}{ Matches by social security number ${ }^{2}$} \\
\hline High (84\%) & 111 & 150.4 & 0.74 & $0.61-0.89$ \\
\hline Medium (70\%) & 149 & 225.6 & 0.66 & $0.56-0.78$ \\
\hline Low (25\%) & 53 & 77.1 & 0.69 & $0.51-0.90$ \\
\hline \multicolumn{5}{|l|}{ Cancer stage $^{\mathrm{b}}$} \\
\hline Local & 37 & 75.6 & 0.49 & $0.34-0.68$ \\
\hline Regional & 34 & 55.4 & 0.61 & $0.42-0.86$ \\
\hline Distant & 9 & 10.2 & 0.89 & $0.40-1.68$ \\
\hline Missing/unknown & 7 & 8.7 & 0.81 & $0.32-1.66$ \\
\hline \multicolumn{5}{|c|}{ AIDS-relative time (months) ${ }^{c}$} \\
\hline-60 to -25 & 64 & 119.9 & 0.53 & $0.41-0.68$ \\
\hline-24 to -7 & 83 & 84.1 & 0.99 & $0.79-1.22$ \\
\hline-6 to +3 & 56 & 48.5 & $1.15^{\mathrm{d}}$ & $0.87-1.50$ \\
\hline+4 to +27 & 47 & 81.1 & 0.58 & $0.43-0.77$ \\
\hline+28 to +60 & 40 & 70.5 & 0.57 & $0.41-0.77$ \\
\hline \multirow[t]{2}{*}{+61 to +120} & 23 & 49.2 & 0.47 & $0.30-0.70$ \\
\hline & & $P_{\text {trend }} 0.14$ & & \\
\hline \multicolumn{5}{|l|}{ CD4 count e $^{\mathrm{a}}$} \\
\hline $0-99$ cells $\left.\mu\right|^{-1}$ & 24 & 44.7 & 0.54 & $0.34-0.80$ \\
\hline $100-199$ cells $\left.\mu\right|^{-1}$ & 31 & 51.5 & 0.60 & $0.41-0.85$ \\
\hline \multirow{2}{*}{$\geqslant 200$ cells $\left.\mu\right|^{-1}$} & 12 & 17.4 & 0.69 & $0.35-1.21$ \\
\hline & & $P_{\text {trend }} 0.47$ & & \\
\hline \multicolumn{5}{|l|}{ AIDS onset year ${ }^{f}$} \\
\hline $1980-1989$ & 0 & 4.7 & 0 & $0-0.78$ \\
\hline $1990-1995$ & 14 & 36.7 & 0.38 & $0.21-0.64$ \\
\hline $1996-2002$ & 33 & 39.6 & 0.83 & $0.57-1.17$ \\
\hline & & $P_{\text {trend }} 0.002$ & & \\
\hline
\end{tabular}

a'Four registries in 'high', three in 'medium, five in 'low'. Excludes rural Georgia, which had no matched breast cancer cases. ${ }^{b}$ Cancer risk by stage during +4 to +60 months after AIDS onset. One registry with miscoded stage data excluded. 'AIDS-relative time intervals are: distant pre-AIDS ( -60 to -25$)$, later pre-AIDS ( -24 to -7$)$, at AIDS onset $(-6$ to +3 , excluded from trend test), shortly after AIDS onset $(+4$ to $+27)$, later after AIDS onset ( +28 to +60$)$, and very late after AIDS onset ( +61 to $+120) .{ }^{d} P_{\text {trend }}$ for AIDS-relative time excludes the AIDS onset period $(-6$ to +3 months). ${ }^{e}$ Observed and expected cases and SIR presented are for +4 to +60 months by CD4 count at AIDS (within -6 to +3 months of AIDS onset). Results for breast cancer were similar during +4 to +27 months $\left(P_{\text {trend }}=0.63\right)$ and +28 to +60 months $\left(P_{\text {trend }}=0.58\right) .{ }^{f}$ Observed and expected cases and SIR presented are for +4 to +27 months by cohort of AIDS onset: little or no antiretroviral therapy (19801989), availability of single and dual nucleoside reverse transcriptase inhibitors (1990-1995), and availability of highly active antiretroviral therapy (HAART) combinations (1996-2002). Breast cancer trend by calendar year of AIDS onset was similar in two sensitivity analyses. For one, cases occurring in the +4 to +60 postAIDS interval were used $\left(P_{\text {trend }}=0.01\right)$. For the second, using the +4 to +27 postAIDS interval, AIDS-onset years were divided as 1980-1986, 1987-1995, and $1996-2002\left(P_{\text {trend }}=0.006\right)$.

attenuated over time to approach the incidence in the general population. Ovary cancer incidence did not differ with AIDS, but a uterine corpus cancer deficit was large and statistically significant among postmenopausal women. Although women with HIV/AIDS had lower fertility and BMI in the pre-HAART era (Lee et al, 2000; Forsyth et al, 2002), the breast cancer deficit with AIDS was minimally altered by adjustment for these factors, and it was unrelated to $\mathrm{CD} 4$ count or AIDS-relative time. A breast cancer deficit with AIDS has been noted inconsistently in previous, much smaller studies (Franceschi et al, 1998; Amir et al, 2000; Grulich et al, 2002; Herida et al, 2003; Hessol et al, 2004).

Cancer risk with HIV/AIDS might reflect differences in hormonal balance or cycling. In the general population, high 


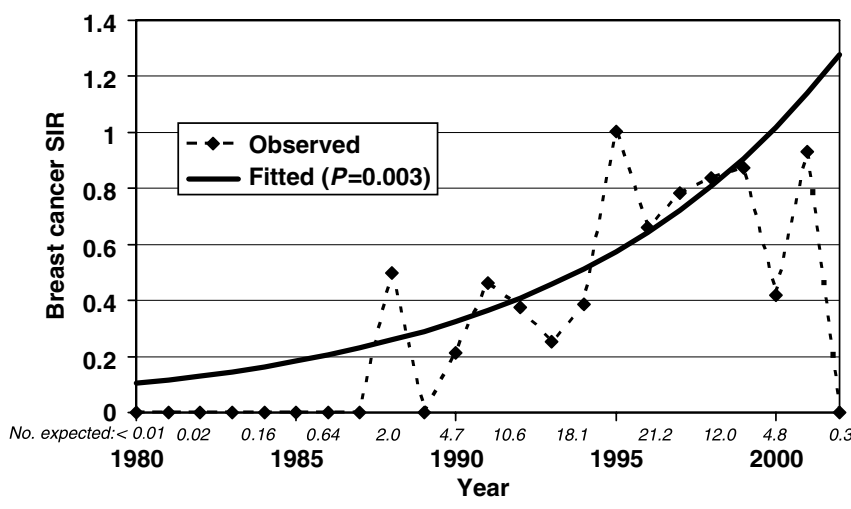

Figure I Observed and fitted (linear Poisson regression model) standardized incidence ratio (SIR) for breast cancer occurring I -5 years after AIDS diagnosis ( $n=90$ observed), by calendar year. A quadratic Poisson regression model did not fit the data better $(P=0.10)$ than this linear model. The number of cancer cases expected in each even-number year is shown in italics.

levels of serum estrogens and testosterone have been linked with an increased risk of breast cancer in postmenopausal women (Key et al, 2002). Although serum levels of sex hormones have not been convincingly linked to premenopausal breast cancer (Sturgeon et al, 2004), lower breast cancer risk with increased physical activity, participation in college athletics, or anorexia nervosa, which result in infrequent ovulation or shortened luteal phase cycles (Bernstein et al, 1994; Wyshak and Frisch, 2000; Michels and Ekbom, 2004), suggests that premenopausal sex hormones also contribute to breast cancer risk. In women with HIV-related CD4 lymphocyte counts of $200-500$ cells $\mu \mathrm{l}^{-1}$, total estradiol and testosterone levels were at the low end of the normal range (Miller et al, 1998). Of note, free testosterone levels were below normal in one-third of HIV-infected women with normal weight, half of those with up to $10 \%$ of body weight loss, and two-thirds of those with more severe weight loss, of whom $38 \%$ were amenorrheic (Grinspoon et al, 1997). Generally, however, menstrual cycles of HIV-infected women are normal or only slightly irregular (Ellerbrock et al, 1996).

Since the 1980s, HIV/AIDS patients have had marked changes in body composition that may have affected their endogenous hormone levels and risk of cancer. In the early 1990s, before availability of HAART and the current obesity epidemic (Flegal et al, 2002), one-fifth of HIV-infected women in New York City reported losing more than $10 \%$ of their usual body weight (Ellerbrock et al, 1996). Then, during the first year on HAART, BMI increased dramatically, almost entirely with fat (Silva et al, 1998). During the HAART era, HIV-infected women in the US have tended to be overweight or obese (Shuter et al, 2001; Mulligan et al, 2005). A single BMI value, as we used for adjustment, would not reflect these substantial and rapid changes. Thus, attenuation of the breast cancer deficit may still be tied, in part, to increases in body fat as anti-HIV treatments have been increasingly effective, available, and used (Herida et al, 2003).

Perhaps the deficit in breast cancer reflects the ability of HIV to infect, replicate in, and impair proliferation of breast cells (Toniolo et al, 1995; Southern, 1998). Epithelial cell infection by HIV is inefficient but occurs through several CD4-independent mechanisms (Phillips and Bourinbaiar, 1992). Likewise, HIV can transiently infect epithelial and stromal cells of the endometrium, with notable differences in HIV receptor expression and cytotoxic T-lymphocyte activity by menstrual phase and menopause status (Howell et al, 1997; Asin et al, 2003; Yeaman et al, 2003). Anti-HIV medications would likely reduce HIV replication and perhaps allow cell proliferation, either directly or indirectly (Asin et al, 2003; Bettaccini et al, 2005; Chung et al, 2005). If so, increasing use and effectiveness of anti-HIV treatments would attenuate the cancer deficit.

Bias is an important concern for our study. Women with HIV/ AIDS may have been screened infrequently and had conditions that diverted attention from breast masses or vaginal bleeding (Preston-Martin et al, 2002). The smaller deficit with distant metastases (SIR 0.89) than earlier stage breast cancer (SIR 0.54) implies delayed diagnosis. Screening bias would not readily account for a breast cancer deficit among young women with AIDS (SIR 0.69), as routine mammograms are not recommended before age 40. Screening also is not performed for uterine corpus cancer. Cancer deficits could be an artefact of cases missed in the registry match. As many women change names upon marriage or divorce, sensitivity of the linkage might be lower than the $95 \%$ reported previously (Borges et al, 2001). However, many records were linked with social security number, and the breast cancer deficit was unrelated to completeness of records with social security numbers available for matching. Finally, based on undetected deaths with central nervous system lymphoma (unpublished data), we estimate that $15 \%$ of the deficit may reflect migration out of the registration area (Cote et al, 1997).

From 1980 to 2002, women with AIDS had significantly reduced risk of breast and postmenopausal uterine corpus cancers, but not of ovary cancer. The cancer deficits were unrelated to immune deficiency or selected risk factors. We offer two hypotheses for the breast cancer deficit. First, women with HIV/AIDS had alterations of reproductive and perhaps other hormones tied to breast cancer (Rose et al, 2004). Second, HIV infected the breast, impairing proliferation of malignantly transformed cells. Both mechanisms would be reduced with effective anti-HIV therapy, resulting in an increased incidence of breast cancer that approaches that of the general population.

\section{ACKNOWLEDGEMENTS}

This research was supported by the Intramural Research Program of the National Cancer Institute, National Institutes of Health. HIV/AIDS and cancer registries in the following regions participated in the HIV/AIDS Cancer Match Study: the states of Colorado, Connecticut, Florida, Georgia, Massachusetts, Michigan, and New Jersey; and the metropolitan areas of Los Angeles, San Diego, and San Francisco (California), New York City (New York), and Seattle (Washington). We are grateful for the many staff members at these registries who collected the data, prepared data files for the matches, and facilitated the record linkages. We also thank Phil Virgo (Computer Sciences Corporation, Rockville Maryland) for performing the record linkages, Norma Kim and Emily Moser (RTI International, Rockville, Maryland) for study management, and Dr Robert Biggar for helpful discussions and review of the manuscript. Data in this manuscript were collected by the Women's Interagency HIV Study (WIHS) Collaborative Study Group with centers (Principal Investigators) located at: New York City/Bronx Consortium (Kathryn Anastos); Brooklyn, NY (Howard Minkoff); Washington DC Metropolitan Consortium (Mary Young); The Connie Wofsy Study Consortium of Northern California (Ruth Greenblatt); Los Angeles County/Southern California Consortium (Alexandra Levine); Chicago Consortium (Mardge Cohen); Data Analysis Center (Stephen Gange). The WIHS is funded by the National Institute of Allergy and Infectious Diseases with supplemental funding from the National Cancer Institute, and the National Institute on Drug Abuse (U01-AI-35004, UO1-AI-31834, UO1-AI-34994, UO1-AI-34989, UO1-AI-34993, and UO1-AI-42590). Funding is also provided by the National Institute of Child Health and Human Development (UO1-HD-32632) and the National Center for Research Resources (MO1-RR-00071, MO1-RR-00079, MO1-RR-00083). 


\section{REFERENCES}

Althuis MD, Brogan DD, Coates RJ, Daling JR, Gammon MD, Malone KE, Schoenberg JB, Brinton LA (2003) Breast cancers among very young premenopausal women (United States). Cancer Causes Control 14: 151 160

Amir H, Kaaya EE, Kwesigabo G, Kiitinya JN (2000) Breast cancer before and during the AIDS epidemic in women and men: a study of Tanzanian Cancer Registry data 1968 to 1996. J Natl Med Assoc 92: $301-305$

Asin SN, Wildt-Perinic D, Mason SI, Howell AL, Wira CR, Fanger MW (2003) Human immunodeficiency virus type 1 infection of human uterine epithelial cells: viral shedding and cell contact-mediated infectivity. J Infect Dis 187: $1522-1533$

Bacon MC, von Wyl V, Alden C, Sharp G, Robison E, Hessol N, Gange S, Barranday Y, Holman S, Weber K, Young MA (2005) The Women's Interagency HIV Study: an observational cohort brings clinical sciences to the bench. Clin Diagn Lab Immunol 12: 1013-1019

Ballard-Barbash R, Swanson CA (1996) Body weight: estimation of risk for breast and endometrial cancers. Am J Clin Nutr 63: 437S-441S

Barkan SE, Melnick SL, Preston-Martin S, Weber K, Kalish LA, Miotti P, Young M, Greenblatt R, Sacks H, Feldman J (1998) The Women's Interagency HIV Study. WIHS Collaborative Study Group. Epidemiology 9: $117-125$

Beral V, Newton R (1998) Overview of the epidemiology of immunodeficiency-associated cancers. J Natl Cancer Inst Monogr 23: 1-6

Bernstein L, Henderson BE, Hanisch R, Sullivan-Halley J, Ross RK (1994) Physical exercise and reduced risk of breast cancer in young women. J Natl Cancer Inst 86: $1403-1408$

Bettaccini AA, Baj A, Accolla RS, Basolo F, Toniolo AQ (2005) Proliferative activity of extracellular HIV-1 Tat protein in human epithelial cells: expression profile of pathogenetically relevant genes. BMC Microbiol 5: 20

Borges HT, Watkins J, Stafford R, Biggar RJ (2001) Linkage of selected AIDS and cancer registries in the United States. J Registry Manage 28: $89-92$

Breslow NE, Day NE (1987) Statistical methods in cancer research. Volume II - The design and analysis of cohort studies. IARC Sci Publ 82: 1-406

Brinton LA, Berman ML, Mortel R, Twiggs LB, Barrett RJ, Wilbanks GD, Lannom L, Hoover RN (1992) Reproductive, menstrual, and medical risk factors for endometrial cancer: results from a case-control study. Am J Obstet Gynecol 167: $1317-1325$

Centers for Disease Control and Prevention (2002) 2000 National Health Interview Survey (NHIS) public use data release: NHIS survey description. US Department of Health and Human Services: Hyattsville, MD

Chung MH, Kiarie JN, Richardson BA, Lehman DA, Overbaugh J, JohnStewart GC (2005) Breast milk HIV-1 suppression and decreased transmission: a randomized trial comparing HIVNET 012 nevirapine versus short-course zidovudine. AIDS 19: 1415-1422

Cote TR, Biggar RJ, Rosenberg PS, Devesa SS, Percy C, Yellin FJ, Lemp G, Hardy C, Goedert JJ, Blattner WA (1997) Non-Hodgkin's lymphoma among people with AIDS: incidence, presentation and public health burden. AIDS/Cancer Study Group. Int J Cancer 73: 645-650

Ellerbrock TV, Wright TC, Bush TJ, Dole P, Brudney K, Chiasson MA (1996) Characteristics of menstruation in women infected with human immunodeficiency virus. Obstet Gynecol 87: 1030-1034

Engels EA, Frisch M, Biggar RJ, Goedert JJ (2003) Re: 'Estimation of risk of cancers before occurrence of acquired immunodeficiency syndrome in persons infected with human immunodeficiency virus'. Am J Epidemiol 157: $955-956$

Flegal KM, Carroll MD, Ogden CL, Johnson CL (2002) Prevalence and trends in obesity among US adults, 1999-2000. JAMA 288: 1723-1727

Forsyth BW, Davis JA, Freudigman KA, Katz KH, Zelterman D (2002) Pregnancy and birth rates among HIV-infected women in the United States: the confounding effects of illicit drug use. AIDS 16: $471-479$

Franceschi S, Dal Maso L, Arniani S, Crosignani P, Vercelli M, Simonato L, Falcini F, Zanetti R, Barchielli A, Serraino D, Rezza G (1998) Risk of cancer other than Kaposi's sarcoma and non-Hodgkin's lymphoma in persons with AIDS in Italy. Cancer and AIDS Registry Linkage Study. Br J Cancer 78: $966-970$

Friedenreich CM (2001) Review of anthropometric factors and breast cancer risk. Eur J Cancer Prev 10: 15-32

Frisch M, Biggar RJ, Engels EA, Goedert JJ (2001) Association of cancer with AIDS-related immunosuppression in adults. JAMA 285: 1736-1745

Frisch M, Biggar RJ, Goedert JJ (2000) Human papillomavirus-associated cancers in patients with human immunodeficiency virus infection and acquired immunodeficiency syndrome. J Natl Cancer Inst 92: 1500-1510
Fritz A, Percy C, Jack A, Shanmugaratnam K, Sobin L, Parkin DM, Whelan S (2000) International classification of diseases for oncology 3rd edn World Health Organization: Geneva

Goedert JJ (2000) The epidemiology of acquired immunodeficiency syndrome malignancies. Semin Oncol 27: 390-401

Goedert JJ, Cote TR, Virgo P, Scoppa SM, Kingma DW, Gail MH, Jaffe ES, Biggar RJ (1998) Spectrum of AIDS-associated malignant disorders. Lancet 351: $1833-1839$

Grinspoon S, Corcoran C, Miller K, Biller BM, Askari H, Wang E, Hubbard J, Anderson EJ, Basgoz N, Heller HM, Klibanski A (1997) Body composition and endocrine function in women with acquired immunodeficiency syndrome wasting. J Clin Endocrinol Metab 82: $1332-1337$

Grulich AE, Li Y, McDonald A, Correll PK, Law MG, Kaldor JM (2002) Rates of non-AIDS-defining cancers in people with HIV infection before and after AIDS diagnosis. AIDS 16: 1155-1161

Grulich AE, Wan X, Law MG, Coates M, Kaldor JM (1999) Risk of cancer in people with AIDS. AIDS 13: 839-843

Herida M, Mary-Krause M, Kaphan R, Cadranel J, Poizot-Martin I, Rabaud C, Plaisance N, Tissot-Dupont H, Boue F, Lang JM, Costagliola D (2003) Incidence of non-AIDS-defining cancers before and during the highly active antiretroviral therapy era in a cohort of human immunodeficiency virus-infected patients. J Clin Oncol 21: $3447-3453$

Hessol NA, Seaberg EC, Preston-Martin S, Massad LS, Sacks HS, Silver S, Melnick S, Abulafia O, Levine AM (2004) Cancer risk among participants in the women's interagency HIV study. J Acquir Immune Defic Syndr 36: 978-985

Howell AL, Edkins RD, Rier SE, Yeaman GR, Stern JE, Fanger MW, Wira CR (1997) Human immunodeficiency virus type 1 infection of cells and tissues from the upper and lower human female reproductive tract. J Virol 71: $3498-3506$

Key T, Appleby P, Barnes I, Reeves G (2002) Endogenous sex hormones and breast cancer in postmenopausal women: reanalysis of nine prospective studies. J Natl Cancer Inst 94: 606-616

Lee LM, Wortley PM, Fleming PL, Eldred LJ, Gray RH (2000) Duration of human immunodeficiency virus infection and likelihood of giving birth in a Medicaid population in Maryland. Am J Epidemiol 151: $1020-1028$

MacMahon B, Cole P, Lin TM, Lowe CR, Mirra AP, Ravnihar B, Salber EJ, Valaoras VG, Yuasa S (1970) Age at first birth and breast cancer risk. Bull World Health Organ 43: $209-221$

Michels KB, Ekbom A (2004) Caloric restriction and incidence of breast cancer. JAMA 291: $1226-1230$

Miller K, Corcoran C, Armstrong C, Caramelli K, Anderson E, Cotton D, Basgoz N, Hirschhorn L, Tuomala R, Schoenfeld D, Daugherty C, Mazer N, Grinspoon S (1998) Transdermal testosterone administration in women with acquired immunodeficiency syndrome wasting: a pilot study. J Clin Endocrinol Metab 83: $2717-2725$

Mulligan K, Anastos K, Justman J, Freeman R, Wichienkuer P, Robison E, Hessol NA (2005) Fat distribution in HIV-infected women in the United States: DEXA substudy in the Women's Interagency HIV Study. J Acquir Immune Defic Syndr 38: 18-22

Nawar E, Mbulaiteye S, Gallant JE, Wohl DA, Ardini M, Hendershot T, Goedert JJ, Rabkin C (2005) Risk Factors for Kaposi's Sarcoma among HHV-8 Seropositive Homosexual Men with AIDS. Int J Cancer 115: $296-300$

Phillips DM, Bourinbaiar AS (1992) Mechanism of HIV spread from lymphocytes to epithelia. Virology 186: $261-273$

Preston-Martin S, Kirstein LM, Pogoda JM, Rimer B, Melnick S, MasriLavine L, Silver S, Hessol N, French AL, Feldman J, Sacks HS, Deely M, Levine AM (2002) Use of mammographic screening by HIV-infected women in the Women's Interagency HIV Study (WIHS). Prev Med 34: $386-392$

Ries L, Eisner MP, Kosary CL, Hankey BF, Miller BA, Clegg L (2005) SEER Cancer Statistics Review, 1975-2002. National Cancer Institute: Bethesda, MD

Rose DP, Komninou D, Stephenson GD (2004) Obesity, adipocytokines, and insulin resistance in breast cancer. Obes Rev 5: $153-165$

Shuter J, Chang CJ, Klein RS (2001) Prevalence and predictive value of overweight in an urban HIV care clinic. J Acquir Immune Defic Syndr 26: $291-297$

Silva M, Skolnik PR, Gorbach SL, Spiegelman D, Wilson IB, Fernandez-DiFranco MG, Knox TA (1998) The effect of protease 
inhibitors on weight and body composition in HIV-infected patients. AIDS 12: $1645-1651$

Southern SO (1998) Milk-borne transmission of HIV. Characterization of productively infected cells in breast milk and interactions between milk and saliva.. J Hum Virol 1: $328-337$

Steenland K, Greenland S (2004) Monte Carlo sensitivity analysis and Bayesian analysis of smoking as an unmeasured confounder in a study of silica and lung cancer. Am J Epidemiol 160: 384-392

Sturgeon SR, Potischman N, Malone KE, Dorgan JF, Daling J, Schairer C, Brinton LA (2004) Serum levels of sex hormones and breast cancer risk in premenopausal women: a case-control study (USA). Cancer Causes Control 15: $45-53$

Toniolo A, Serra C, Conaldi PG, Basolo F, Falcone V, Dolei A (1995) Productive HIV-1 infection of normal human mammary epithelial cells. AIDS 9: $859-866$

\section{Statistical Appendix}

\section{Measures of relative risk}

The objective was to compare cancer risk among women with AIDS, overall and in predefined subgroups, to cancer risk in the general population. Time at risk for development of cancer started with onset of complete cancer registration in a PWA's region, but no earlier than 60 months before AIDS onset. Time at risk continued to the end of complete cancer registration in the same region, but no later than the date of death or 120 months after AIDS onset if not known dead by that time.

Using methods similar to those of previous studies (Goedert et al, 1998; Frisch et al, 2001), we calculated the standardized incidence ratio (SIR) of cancer from 60 months before to 120 months after AIDS onset overall, and also across six AIDS-relative time intervals, as shown in Table 2. For each time interval, the SIR was the ratio of observed to expected cancers derived from contemporaneous population-based incidence rates.

By definition, all persons with cancer before AIDS must have survived long enough after their cancer diagnosis to develop AIDS. Failure to take this survival factor into account has a major impact on the relative risk estimates (Grulich et al, 1999; Engels et al, 2003). Consequently, estimates of the expected cancers, to which observed cases were compared, must take into account that some individuals with cancer died or were lost to follow-up before they developed AIDS. As described previously (Frisch et al, 2000), we used data from the Surveillance, Epidemiology, and End Results program 9 (SEER 9) to calculate survival-conditioned cancer incidence rates covering each month back to 60 months before AIDS. These calculations were stratified by year of cancer diagnosis, sex, racial ancestry (African, European, other/unknown), age (less than 60,60-69, 70 years and older), and 14 regions, including three sub-regions for Georgia (Atlanta, rural, and other).

The same stratification was used, except with 5-year age groups and without year of cancer diagnosis, for cancer incidence rates after AIDS onset. Expected numbers of cancer were calculated as the sum of stratum-specific products of background cancer incidence and person-months at risk among the PWAs (Breslow and Day, 1987). Racial/ethnic ancestry- and age-specific background rates were used to calculate expected numbers in all analyses. Since background cancer rates were not available for Hispanics, expected cancers in this group were based on cancer rates for European ancestry. We calculated 95\% CI assuming a Poisson distribution of the observed cancers (Breslow and Day, 1987).

To evaluate the trend in AIDS-relative time, we modeled the SIR in a Poisson regression model as: $\ln \left(O_{\mathrm{i}} / E_{\mathrm{i}}\right)=\alpha+\beta \mathrm{t}_{\mathrm{i}}$, in which $O_{\mathrm{i}}$ and $E_{\mathrm{i}}$ were the observed and expected numbers of cancers, respectively, in the individual time periods, and $t_{\mathrm{i}}$, was the midpoint of the time interval, measured from AIDS onset. In this
Viswanathan AN, Feskanich D, De Vivo I, Hunter DJ, Barbieri RL, Rosner B, Colditz GA, Hankinson SE (2005) Smoking and the risk of endometrial cancer: results from the Nurses' Health Study. Int J Cancer 114: 996 - 1001

Wyshak G, Frisch RE (2000) Breast cancer among former college athletes compared to non-athletes: a 15-year follow-up. $\mathrm{Br} J$ Cancer 82: $726-730$

Yeaman GR, Howell AL, Weldon S, Demian DJ, Collins JE, O'Connell DM, Asin SN, Wira CR, Fanger MW (2003) Human immunodeficiency virus receptor and coreceptor expression on human uterine epithelial cells: regulation of expression during the menstrual cycle and implications for human immunodeficiency virus infection. Immunology 109: $137-146$

Zhu K, Caulfield J, Hunter S, Roland CL, Payne-Wilks K, Texter L (2005) Body mass index and breast cancer risk in African American women. Ann Epidemiol 15: 123 - 128

model, a two-sided score test of $\beta=0$ evaluated whether SIR changed over time (Goedert et al, 1998; Frisch et al, 2001). To avoid the influence of ascertainment bias, we disregarded cancers occurring in the AIDS period in the trend test. Consequently, we used information from the other periods (two before and the three after AIDS onset) in trend tests, using midpoints of the personyears in each of these intervals $(t=-42,-16,14,41$, and 77 months, respectively) as values of $t_{\mathrm{i}}$.

To analyse trend by CD4 lymphocyte count, we used CD4 values closest to AIDS onset, limited to the AIDS period, and also limited to years 1990-2002 because CD4 data generally were not available before 1990. Trend in SIR was assessed using the median CD4 count below 100 cells $\mu \mathrm{l}^{-1} \quad\left(t=30\right.$ cells $\left.\mu \mathrm{l}^{-1}\right)$, from $100-199$ cells $_{\mu} \mathrm{l}^{-1}$ $\left(t=159\right.$ cells $\left.\mu \mathrm{l}^{-1}\right)$, and $\geqslant 200$ cells $\mu \mathrm{l}^{-1}\left(t=292\right.$ cells $\left.\mu \mathrm{l}^{-1}\right)$.

To analyse trend by calendar time of treatment availability (little or no antiretroviral therapy (1980-1989), widespread single and dual nucleoside reverse transcriptase inhibitors (1990-1995), and HAART combinations (1996-2002)), we used the midpoint of person-years in each interval $(t=1988.56,1993.32$, and 1997.22, respectively). We limited the calendar-time analysis to the 4-27 months after AIDS onset to reduce biases associated with changes in pre-AIDS breast cancer mortality and long term mortality from all causes after AIDS onset.

\section{Indirect adjustment}

The objective was to assess the impact of established cancer risk factors on the observed SIRs. To do so, we obtained risk-factor adjusted SIRs with the following formula:

$$
\begin{aligned}
\frac{O_{\text {baseline|exp }}}{E_{\text {baseline|nonexp }}}=\frac{\sum_{s} O_{\text {baseline } \mid \exp }^{s}}{\sum_{s} E_{\text {baseline } \mid \text { nonexp }}^{s}} \\
=\frac{\sum_{s}\left\{\mathrm{O}^{s} /\left[\sum_{\text {r.level }=\mathrm{a}} R R_{\mathrm{a}} \times p_{\mathrm{a} \mid \exp }^{s}\right]\right\}}{\sum_{s}\left\{E^{s} /\left[\sum_{\text {r.level }=\mathrm{a}} R R_{\mathrm{a}} \times p_{\mathrm{a} \mid \text { nonexp }}^{s}\right]\right\}}
\end{aligned}
$$

in which $R R_{a}$ was the relative risk of cancer for the a-th risk factor value in reference to the baseline; $s$ indexed the age/race strata; and $p_{\mathrm{a} \mid \exp }$ and $p_{\mathrm{a} \mid \text { nonexp }}$ were the prevalence of risk factor value ' $\mathrm{a}$ ' in the AIDS patients (derived from the cohort studies described in the Methods, above) and the general population (derived from NHIS), respectively (Steenland and Greenland, 2004).

Data on BMI among women with AIDS were available from the Women's Interagency HIV Study and from 333 of the 483 women in the AIDS Cancer Cohort Study. As the data from AIDS patients were too sparse to cross-classify BMI, age at first live birth, and age, we assumed that the distribution of BMI was independent of age at first live birth. We obtained the joint 
distribution of these two factors for the six strata of age and racial ancestry by multiplying the probabilities from the individual distributions of the risk factors for both AIDS patients and the NHIS.

For breast cancer analyses, we applied the formula above to adjust for the effects of parity (five categories: nulliparous, else age at first live birth $<20,20-24,25-29$, or $\geqslant 30$ years) and BMI (three levels: $<23,23-26.99$, or $\geqslant 27 \mathrm{~kg} \mathrm{~m}^{-2}$ for weight height ${ }^{-2}$ ). We divided the AIDS patients and the general population into six strata (age $<35,35-49$, or $\geqslant 50$ years; African ancestry or other ancestry). For age strata $<35$ and $35-49$, we applied breast cancer RRs derived from pre-menopausal women ages $<35$ and 35-44, respectively (Althuis et al, 2003). For age stratum $\geqslant 50$, we used breast cancer RRs from MacMahon $(\mathrm{RRs}=2.0,2.0,1.6,1.2$, and 1.0 for nulliparous and age at first live birth $\geqslant 30,25-29,20-24$, and $<2$; respectively) and RRs 1.0, 1.1, and 1.2 for $\mathrm{BMI}<23,23-26.99$, and $\geqslant 27$, respectively, as determined from published studies
(MacMahon et al, 1970; Ballard-Barbash and Swanson, 1996; Friedenreich, 2001).

For uterine corpus cancer analyses, we adjusted for the joint effects of parity (parous, nulliparous) and cigarette smoking (no, yes). We divided the AIDS patients and general population into four age/race strata (age $<50$ or $\geqslant 50$; African ancestry and other ancestry). We then applied endometrial cancer RRs of 1.0 and 2.8 for parous and nulliparous women, respectively, for each of the four age/race strata (Brinton et al, 1992). As reported by others (Viswanathan et al, 2005), we assumed no effect of smoking in women aged $<50$; and we used endometrial cancer RRs of 1.0 and 0.73 for non-smokers and smokers, respectively, for both Africanancestry and other-ancestry women aged $\geqslant 50$. As endometrial cancer data were sparse, adjustment for BMI was done separately, using endometrial cancer RRs 1.0, 1.0, and 2.5 for BMI categories $<24,24-27.99$, and $\geqslant 28 \mathrm{~kg} \mathrm{~m}^{-2}$, respectively, for each of the four age/race strata (Ballard-Barbash and Swanson, 1996). 